


ISSN: 0973-4945; CODEN ECJHAO

E-Journal of Chemistry 2011, 8(2), 803-808

\title{
Removal of Erichrome Black T from Synthetic Wastewater by Cotton Waste
}

\author{
U.V. LADHE*, S. K. WANKHEDE, V. T. PATIL and P. R. PATIL \\ School of Environmental and Earth Sciences \\ North Maharashtra University, Jalgaon- 425 002, India \\ umeshladhe1@yahoo.com
}

Received 19 September 2010; Accepted 30 October 2010

\begin{abstract}
Adsorptions of Erichrome Black T dye in aqueous solution on cotton stem activated carbon have been studied as a function of contact time, concentration and $\mathrm{pH}$. Effect of various experimental parameters has been investigated at $39 \pm 1{ }^{\circ} \mathrm{C}$ under batch adsorption technique. The result shows that cotton stem activated carbon adsorbs dye to a sufficient extent. The physicochemical characterization and chemical kinetics was also examined for the same dye. The overall result shows that it can be fruitfully used for the removal of dye from wastewaters.
\end{abstract}

Keywords: Erichrome Black T, Adsorption, Natural waste, Dyes removal, Physicochemical properties.

\section{Introduction}

Synthetic dyes have been increasingly used in the textile, paper, rubber, plastic, cosmetics, and pharmaceutical and food industries because of their ease of use, inexpensive cost of synthesis, stability and variety of colour compared with natural dyes. Today there are more than 10,000 dyes available commercially, most of which are difficult to biodegrade due to their complex aromatic molecular structure and synthetic origin. The presence of very small amounts of dyes in water (less than $1 \mathrm{ppm}$ for some dyes) is highly visible and affects the quality of waterbodies ${ }^{1}$. The extensive use of dyes often causes pollution problems in the form of colored wastewater discharged into environmental water bodies. It is not only affects aesthetic merit but also reduces light penetration and photosynthesis ${ }^{2}$. A lot of cases throughout the world are reported about the role of dyes in connection with variety of skin, lung, and other respiratory disorders. The problem can impact several vital activities such as fisheries, livestock and agriculture since the polluted water is no longer suitable for their particular use. There are various methods for treating dyes containing wastewater such as coagulation and flocculation, oxidation or ozonation, membrane separation and activated 
carbon adsorption. Out of these methods, adsorption is the procedure of choice as it can be used to remove different types of dyes. Activated carbon (powdered or granular) is most widely used adsorbent because it has excellent adsorption efficiency for organic compounds, but its use is usually limited due to its high cost. In order to decrease the cost of treatment, attempts have been made to find inexpensive alternative adsorbents. Consequently, a number of low cost and easily available materials such as waste biomass are being studied for the removal of different dyes from aqueous solutions at different operating conditions ${ }^{3}$. Natural wastes from agro based industries are of attention mainly because of their abundance. Production of activated carbon from this source may reduce the cost of wastewater treatment and at the same time open new market for low-cost agricultural by-product. A number of non-conventional, low cost plant materials (residues) such as babul Seed ${ }^{4}$, sunflower stalks ${ }^{5}$, the peel of cucumis savita fruit ${ }^{6}$, tamarind fruit shell ${ }^{7}$, orange peel and lemon peel $^{8}$ and are used as adsorbent. A number of low cost and easily available materials such as mosambi peel, cotton stem, neem leaves, grass, badam leaves and nilgiri leaves etc. can be studied for the removal of different dyes from aqueous solutions at different operating conditions.

The objective of the present study is to determine the optimum conditions for the removal of textile azo dye EBT from aqueous solution by adsorption technique using sulphuric acid treated cotton waste as an adsorbent.

\section{Experimental}

The stems of cotton were collected from local field of Jalgaon district in clean plastic bags. These waste materials are washed with distilled water, dried in sunlight, then $60{ }^{\circ} \mathrm{C}$ for $24 \mathrm{~h}$ in hot air oven. The dried material was subjected for acid treatment (ratio 1:1) and kept at room temperature overnight and stored in a tight lid container for further studies. It is then screened through a mesh sieve with a particle size range of 180-300 $\mu \mathrm{m}$.

\section{Preparation of activated carbon from adsorbents}

Carbon was prepared by treating air-dried prepared adsorbent with concentrated sulphuric acid in a weight ratio of 1:1 for $24 \mathrm{~h}$. The resulting black product was kept in an air-oven maintained at $500{ }^{\circ} \mathrm{C}$ for $12 \mathrm{~h}$ followed by washing with $\mathrm{NaHCO}_{3}$ and water until free of excess acid; $\mathrm{pH}$ become 7.0 and dried at $150 \pm 5^{\circ} \mathrm{C}$ to obtain sulphuric acid treated cotton stem activated carbon (CSAC). The carbon product obtained was ground well to fine powder and its physical properties were analyzed by usual standard methodologies.

\section{Preparation of dye solution}

Stock solution $(1000 \mathrm{mg} / \mathrm{L})$ of EBT was prepared by dissolving $1 \mathrm{~g}$ of dye in $1000 \mathrm{~mL}$ of double distilled water. The stock solutions were diluted with double distilled water to obtain required standard solution. Batch adsorption studies were performed at room temperature.

\section{Experimental methods and measurements}

The adsorption experiments were carried out by agitating the carbon with $50,100,150 \&$ $200 \mathrm{mg} / \mathrm{L}$ dye solution of desired concentration at $\mathrm{pH} 7.0$ and at room temperature in a mechanical shaker $(120 \mathrm{rpm})$. After the defined time intervals, samples were withdrawn from the shaker, centrifuged and the supernatant solution was analyzed for residual dye concentration using a UV-Visible spectrophotometer (Shimadzu UV Visible spectrophotometer, model UV mini 1240) at $\lambda_{\text {max }}=520 \mathrm{~nm}$ 


\section{Results and Discussion}

\section{Characterization of the adsorbent}

The physicochemical properties of the prepared activated carbon were determined by standard procedures. Surface area was determined by BET method. The physicochemical properties are listed in Table 1.

Table 1. Characteristic of adsorbent

\begin{tabular}{clc}
\hline S.No. & \multicolumn{1}{c}{ Properties } & CSAC \\
\hline 1 & $\mathrm{pH}$ & 7.3 \\
2 & Moisture Content, $\%$ & 7 \\
3 & Ash Content & 3.2 \\
4 & Apperent Density & 0.431 \\
5 & Solubility in water, $\%$ & 0.54 \\
6 & Solubility in $\mathrm{HCl}$ & 1.78 \\
7 & Surface area, $\mathrm{m}^{2} / \mathrm{g}$ & 198 \\
\hline
\end{tabular}

\section{Effect of initial dye concentration}

The adsorption studies were carried out at fixed adsorbent dose $(400 \mathrm{mg} / 100 \mathrm{~mL})$ in the test solution, at room temperature, $\mathrm{pH} 7.0$ and at different initial concentrations of EBT (50, $100,150,200$ and $250 \mathrm{mg} / \mathrm{L})$ for different time intervals $(15,30,45,60,90$ and $120 \mathrm{~min})$. The results are shown in Table 2.

Table 2. Effect of initial dyes concentration on dye removal (absorption dosage $0.5 \mathrm{~g}$ $100 \mathrm{~m} / \mathrm{L} \mathrm{pH}=7.0$ )

\begin{tabular}{cccccc}
\hline \multirow{2}{*}{$\begin{array}{c}\text { Time } \\
\text { min }\end{array}$} & \multicolumn{5}{c}{ Concentrations, mg/L } \\
\cline { 2 - 6 } & 50 & 100 & 150 & 200 & 250 \\
\hline 15 & 30 & 36.61 & 13.12 & 18.63 & 26.72 \\
30 & 43.63 & 51.40 & 41.25 & 41.81 & 44.12 \\
45 & 56.36 & 62.67 & 52.5 & 59.54 & 60.32 \\
60 & 67.27 & 72.53 & 60.62 & 73.63 & 71.25 \\
90 & 82.72 & 83.09 & 81.87 & 83.18 & 83.40 \\
120 & 82.72 & 83.09 & 81.87 & 83.18 & 83.40 \\
\hline
\end{tabular}

The initial concentration provides an important driving force to overcome all mass transfer resistance of dye anions between the aqueous and solid phases ${ }^{2}$. In addition, increasing initial dye concentration increases the number of interactions between dye anions and adsorbents, which enhances the adsorption process. Hence a higher initial concentration of EBT will increase the adsorption rate. The equilibrium for dye removal attainment was achieved after $120 \mathrm{~min}$. In dye adsorption process, initially dye molecules have to encounter the boundary layer effect before diffusing from boundary layer film onto adsorbent surface. This is followed by the diffusion of dye into the porous structure of the adsorbent. This phenomenon will take relatively longer contact time ${ }^{3}$.

\section{Effect of adsorbent dose}

The adsorption of EBT on CSAC was studied by changing the quantity of adsorbent $(0.2,0.4,0.6,0.8$ and $1.0 \mathrm{~g} \mathrm{~m} / \mathrm{in} 100 \mathrm{~mL})$ in the test solution while keeping the initial dye concentration $100 \mathrm{ppm}$. Experiments were carried out at different contact times for $120 \mathrm{~min}$. 
Table 3. Effect of adsorption dose on the dye adsorption

\begin{tabular}{ccccccc}
\hline Adsorbent dose, & \multicolumn{5}{c}{ Percentage of dye removal with time, min } \\
\cline { 2 - 7 } g 50 mL $^{-1}$ & 15 & 30 & 45 & 60 & 90 & 120 \\
\hline 0.2 & 18.54 & 38.41 & 43.04 & 49.69 & 54.96 & 55.63 \\
0.4 & 19.01 & 51.40 & 62.67 & 72.53 & 79.57 & 80.28 \\
0.6 & 22.32 & 40.17 & 51.78 & 66.96 & 85.71 & 85.71 \\
0.8 & 29.59 & 38.77 & 43.87 & 71.42 & 85.71 & 86.73 \\
1 & 36.47 & 47.05 & 63.52 & 77.64 & 90.58 & 92.94 \\
\hline
\end{tabular}

The percentage removal of dye was found to increase with the increase in does of adsorbent. The increase in the percent removal of dyes with the increase in adsorbent dosage is due to the availability of larger surface area with more active functional groups ${ }^{9}$.

\section{Effect of $p H$}

The effect of $\mathrm{pH}$ on adsorption of EBT on CSAC was studied at $100 \mathrm{ppm}$ initial dye concentration with $400 \mathrm{mg} / 100 \mathrm{~mL}$ adsorbent mass at room temperature for $3 \mathrm{~h}$ equilibrium time, The results are shown in Figure 1. As the $\mathrm{pH}$ value increased from 2 to 9 , the efficiency of the dye removal is lessen.

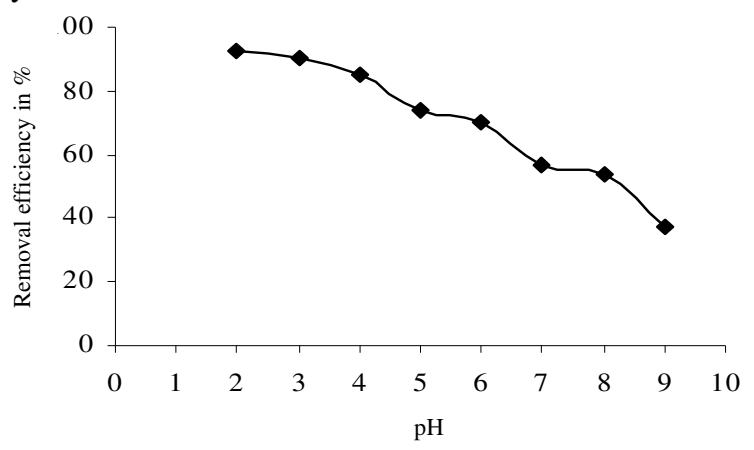

Fig 1- Effect of $\mathrm{pH}$ on EBT removal

The $\mathrm{pH}$ value of dye solutions plays an important role in the whole adsorption process and particularly in adsorption capacities. In this study, the effect of $\mathrm{pH}$ can be explained by considering the surface charge on the adsorbent.

As the $\mathrm{pH}$ of the system increases, the number of hydroxide ion increases and will compete with anionic ion of the dye on the adsorption site in the alkaline condition and could reduce the adsorption capacity since the number of positively charged sites decreases. Moreover, there are also no more exchangeable anions on the outer surface of the adsorbent. A negative charged surface site on the adsorbent does not favour the adsorption of dye ions due to electrostatic repulsion and abundance of $\mathrm{OH}^{-}$ion ${ }^{10}$.

\section{Adsorption isotherm}

The experimental data are analyzed according to the linear form of the Langmuir and Freundlich isotherms. The Langmuir isotherm is represented by the following equation

$$
(\mathrm{Ce} / \mathrm{qe})=(1 / \mathrm{Qob})+(\mathrm{Ce} / \mathrm{Qo})
$$

Here $\mathrm{Ce}$ is the equilibrium concentration $(\mathrm{mg} / \mathrm{L})$, qe is the amount adsorbed at equilibrium ( $\mathrm{mg} / \mathrm{g}$ ). Qo and $\mathrm{b}$ is Langmuir constants related to the adsorption efficiency and energy of adsorption, respectively ${ }^{11}$. 
The linear plots of Ce/qe versus Ce suggest the applicability of the Langmuir isotherms (Figure 2). The values of $\mathrm{Q}_{\mathrm{o}}$ and $\mathrm{b}$ are determined from the slope and intercept of the plots and are presented in Table 4.

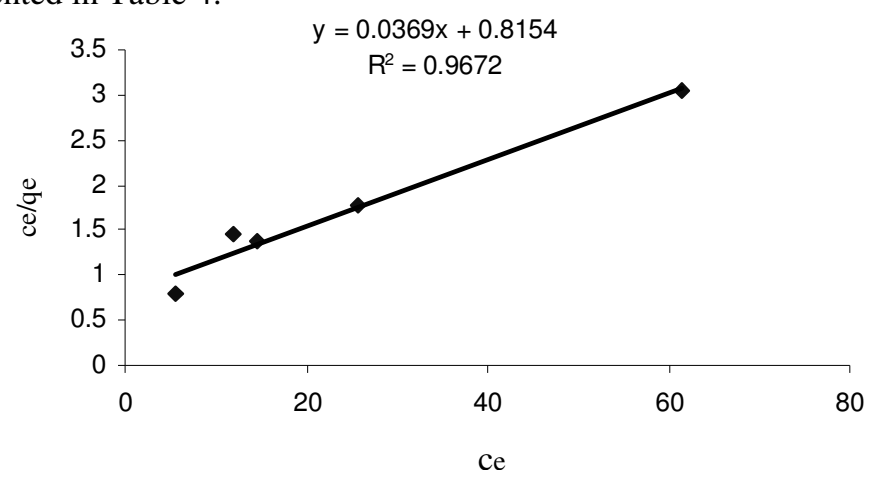

Figure 2. Langmuir isotherm for the removal of EBT by adsorption on CSAC

Table 4. Langmuir and Freundlich parameters of adsorption isotherms

\begin{tabular}{cccccccc}
\hline Adsorbents & \multicolumn{3}{c}{ Langmuir isotherm } & \multicolumn{3}{c}{ Freundlich isotherm } \\
\cline { 2 - 8 } & $\mathrm{Q}_{0}$ & $\mathrm{~B}$ & $\begin{array}{c}\text { Correlation } \\
\text { coefficient } \\
(\mathrm{r})\end{array}$ & $\mathrm{R}_{\mathrm{L}}$ & $\begin{array}{c}\text { Intercep } \\
\mathrm{t}\left(\mathrm{k}_{\mathrm{f}}\right)\end{array}$ & $\begin{array}{c}\text { Slope } \\
(1 / \mathrm{n})\end{array}$ & $\begin{array}{c}\text { Correlation } \\
\text { coefficient } \\
(\mathrm{r})\end{array}$ \\
\hline Cotton & 27.10027 & 0.043648 & 0.9672 & 0.138927 & 0.4589 & 0.4759 & 0.9618 \\
\hline
\end{tabular}

The essential characteristics of the Langmuir isotherm can be expressed in terms of a dimensionless constant separation factor RL that is given in Eq.2.

$$
\mathrm{R}_{\mathrm{L}}=1 /(1+\mathrm{bCo})
$$

The value of $\mathrm{RL}$ indicates the type of the isotherm to be either favorable $(0<\mathrm{RL}<1)$, unfavorable $(R L>1)$, linear $(R L=1)$ or irreversible $(R L=0)$. The value of $R L$ was found to be 0.138927 suggesting the isotherm to be favorable at the concentrations studied ${ }^{12}$.

The Freundlich equation is also employed for the adsorption of EBT on the adsorbent. The Freundlich isotherm is represented as

$$
\log \mathrm{qe}=\log \mathrm{kf}+(1 / \mathrm{n}) \log \mathrm{Ce}
$$

Here qe is the amount of EBT dye adsorbed $(\mathrm{mg} / \mathrm{g})$, Ce is the equilibrium concentration of dye in the solution $(\mathrm{mg} / \mathrm{L})$ and $\mathrm{K}_{\mathrm{f}}$ and $\mathrm{n}$ are constants incorporating all factors affecting the adsorption capacity and intensity of adsorption, respectively. Linear plot of log qe versus log ce shows that the adsorption of EBT follows also the Freundlich isotherm (Figure 3).

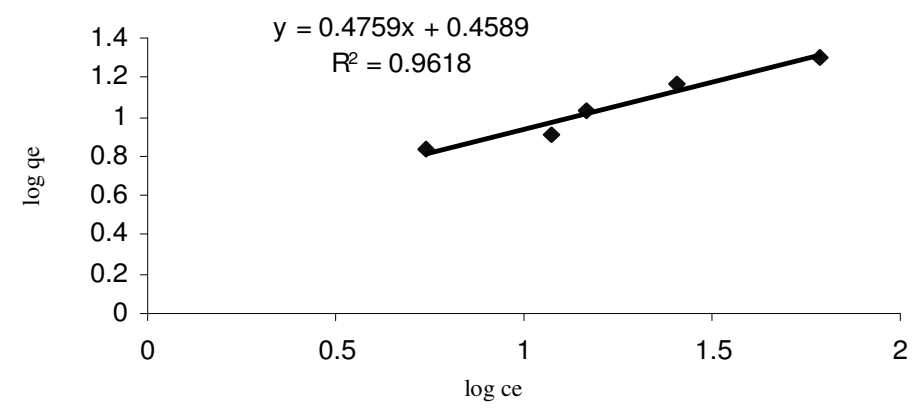

Figure 3. Freundlich isotherm for the removal of EBT by adsorption on CSAC 
The values of $\mathrm{K}_{\mathrm{f}}$ and $\mathrm{n}$ found and given in Table 4, shows the increase of negative charge on the surface that enhances the electrostatic force between the carbon surface and the dye ion, which increases in turn the adsorption of dye. The values clearly show the dominance of adsorption capacity. The magnitude of the exponent " $n$ " gives an indication of the favorability and $\mathrm{K}_{\mathrm{f}}$ the capacity of the adsorbent/adsorbate system. The ' $\mathrm{n}$ ' value was (2.10128) was in between 1 and 10 representing beneficial adsorption.

\section{Conclusion}

CSAC works well as adsorbent for EBT. The adsorption of EBT was depending on the adsorbent dose of CSAC and EBT concentration in the wastewater. CSAC showed more adsorption efficiency and adsorption efficiency increased on increasing adsorbent dose. The adsorption obeyed both Langmuir and Freundlich isotherms. These studies prove that some natural adsorbent such as cotton stem can be an alternative option for dye removal from dilute industrial effluents.

\section{References}

1. Banat I M, Nigam P, Singh D and Marchant R, Bioresource Technol., 1996, 58(3), 217-227.

2. Murugan T, Ganapathi A and Valliappan R, E -J Chem., 2010, 7(3), 669-676.

3. Liew Abdullah A G, Mohd Salleh M A, Siti Mazlina M K, Megat Mohd Noor M J, Osman M R, Wagiran R and Sobri S, Int J Eng Tech., 2005, 2(1), 8-13.

4. Sujatha M, Geetha A, Sivakumar P and Palanisamy P N, E-J Chem, 2008, 5(4), 742-753.

5. Gang Sun and Xu. Xiangjing, Ind Eng Chem Res., 1997, 6, 808-812

6. Thirumalisamy S and Subbian M, Bioresources, 2010, 5(1), 419-437.

7. Somasekhara Reddy M C, J Sci Ind Res., 2006, 65, 443-446.

8. Kanan N, Meenakshisundaram M and Johnson R, EJEAFChe., 2009, 8(8), 574-583.

9. Santhi T, Manonmani S, Smitha T and Mahalaxmi K, J Appl Sci Environ Sant., 2009, 4(3), 263-271.

10. Zawani Z, Luqman Chuah A and Thomas S Y Choong, Eur J Sci Res., 2009, 37(1), 67-76.

11. Khattri S D and Singh M K, Water Air Soil Pollut., 2000, 120, 283-294.

12. Mas Rosemal H. Mas Haris and Kathiresan Sathasivam, Am J Appl Sci., 2009, 6(9), 1690-1700. 


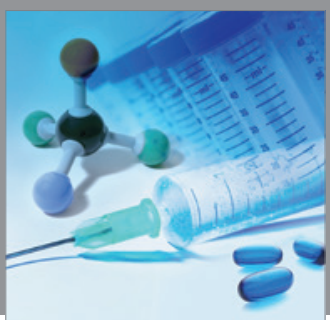

International Journal of

Medicinal Chemistry



Carbohydrate Chemistry



The Scientific World Journal



Submit your manuscripts at

http://www.hindawi.com
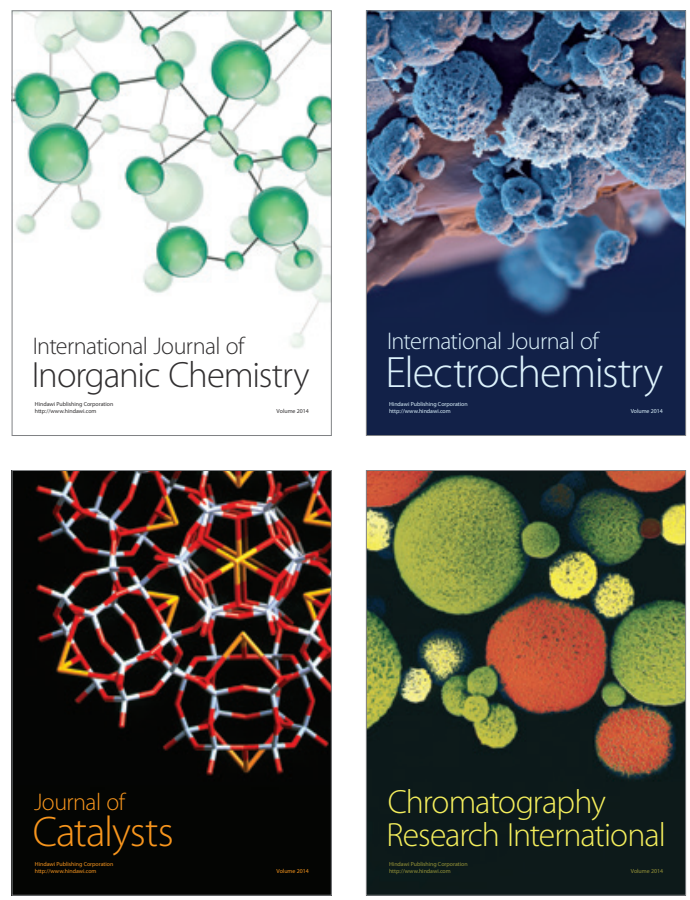
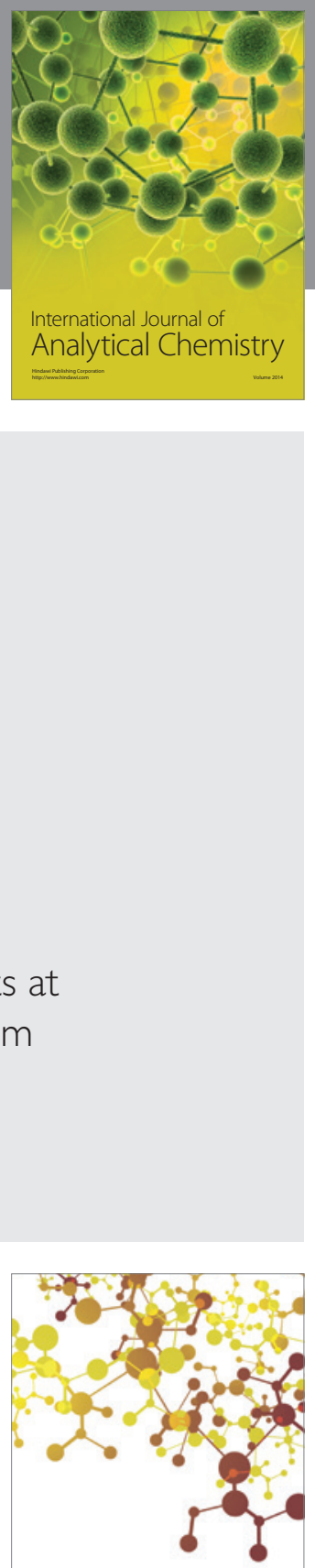

Journal of

Applied Chemistry
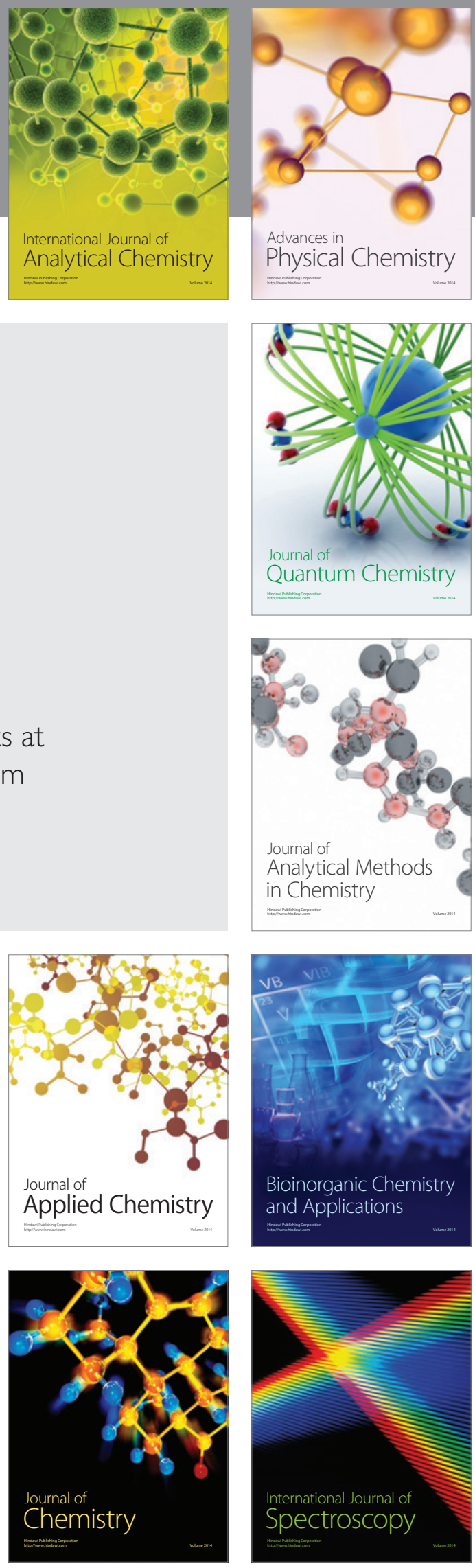